\section{Esophageal Dislodgment of a Variceal Ligator Cap Due to Size Mismatch Between the Ligator Cap and the Endoscope}

Endoscopic variceal ligation (EVL) is an effective therapy for prophylaxis and treatment of bleeding varices [1-3]. We describe a case of dislodgment of the ligator cap in a patient without esophageal stricture.

A 53-year-old man with cryptogenic cirrhosis was found to have grade III esophageal varices on endoscopy. Primary EVL was performed without sequelae. At 2 weeks later, a repeat EVL was attempted. Endoscopy using an Olympus gastroscope GIF XQ240 showed four cords of grade II esophageal varices. The gastroscope was withdrawn, loaded with a variceal ligator (Six-Shooters S MBL-6; Wilson-Cook Medical, Winston-Salem, North Carolina, USA) and EVL was performed. However, upon withdrawal of the endoscope, the ligator cap fell from the endoscope and became lodged in the mid-esophagus (Figure 1). The cap was retrieved with rattooth forceps without complication.

Clarkston et al. reported a case of dislodgment of the ligator cap in a patient with esophageal stricture [4]. As far as we are aware, dislodgment of the ligator cap as a complication of EVL has not been described in patients without esophageal stricture $[5,6]$.

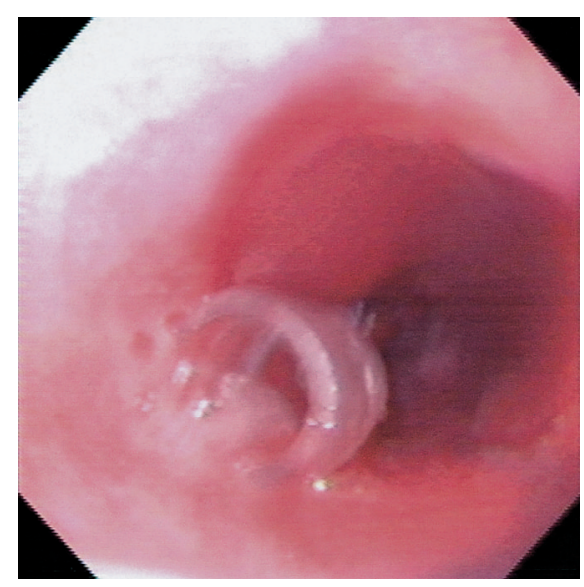

Figure 1 Endoscopic view showing the dislodged ligator cap in the mid-esophagus.
At our endoscopy unit, we have been using the Olympus gastroscope GIF XQ230 (external diameter $9.2 \mathrm{~mm}$ ) since 1996 and the GIF XQ240 (external diameter $9.0 \mathrm{~mm}$ ) since the year 2000 . With the phasing out of the XQ230 model, most of the upper endoscopes in our unit are now the slimmer XQ240 model, whose diameter is smaller than the recommended fitting diameter for the distal cap of the MBL-6 of 9.5 to $13.0 \mathrm{~mm}$. The size mismatch caused dislodgment of the ligator cap. We reported the incident to the supplier of the ligators and we have since been supplied with MBL-6-XS ligators, whose distal caps fit scopes with a diameter of $8.6 \mathrm{~mm}$ to $9.2 \mathrm{~mm}$.

We recommend careful checking of the endoscope diameter and matching it with the correct size of ligator cap before performing variceal ligation, in order to avoid such a complication.

\section{T. Wai, K. Y. Ho, F. Y. Kwok}

Endoscopic Centre,

National University Hospital,

Singapore

\section{References}

\footnotetext{
${ }^{1}$ Stiegmann GV. Endoscopic ligation of esophageal varices. Am J Surg 1988; 156: 9B-12B

2 Binmoeller KF, Soehendra N. Nonsurgical treatment of variceal bleeding: new modalities. Am J Gastroenterol 1995; 90: $1923-1931$

${ }^{3}$ Imperiale TF, Chalasani N. A meta-analysis of endoscopic variceal ligation for primary prophylaxis of esophageal variceal bleeding. Hepatology 2001; 33: 802-807

${ }^{4}$ Clarkston WK, Kuganeswaran E, Jonnalagadda SS, Smith OJ. latrogenic esophageal foreign body and extrinsic tracheal compression during esophageal band ligation. Gastrointest Endosc 1998; 47: $106-107$
}

${ }^{5}$ Laine L, Cook D. Endoscopic ligation compared with sclerotherapy for treatment of esophageal variceal bleeding a meta-analysis. Ann Intern Med 1995; 123: 280 - 287

${ }^{6}$ Saeed AZ, Stiegmann GV, Ramirez FC et al. Endoscopic variceal ligation is superior to combined ligation and sclerotherapy for esophageal varices: a multicenter prospective randomized trial. Hepatology 1997; 25: $71-74$

\section{Corresponding Author}

\section{K. Y. Ho, M.D.}

Department of Medicine National University Hospital 5 Lower Kent Ridge Road Singapore 119074

Singapore

Fax: $\quad+65-7794112$

E-mail: mdchoky@nus.edu.sg 